\title{
ANTIQUITY
}

Evidence from North China (Wang, I 96I, 84) and central Korea (Kim, r968, 57) suggests that pine is secondary vegetation which takes over when primary deciduous forest is disturbed by humans. In the Korean case these data are not unequivocal: Oh (197I) refers to climatic causes for the increase in spruce and pine pollens (at an estimated date of $3,000 \pm 500$ years ago) rather than to anthropogenic factors; however, it seems to me that in both Korea and China the occurrence of pine and of Artemisia may be evidence of human disturbance of the forests. The increase in the pollen of the Chenopods noted by Ho $(1969,9)$ and Chou (Shih et al., $1963,271)$ are also indicators of human interference (Butzer, I971, 586). Generally it should be observed that no single pollen frequency should be taken as a type indicator separate from its ecological context. Pollen analysis without detailed ecological examination has been shown to be a risky endeavour. Human interaction with the environment must also be taken into account.

In my opinion, the case for a treeless steppe, even with the exception of the water courses and the mountain ridges, cannot be supported. There still seems to be evidence that at least part of the region was a deciduous, broadleaved forest dominated by oaks, admixed with small stands of ash, elm, and Chinese hackberry, with willows and poplars along the rivers (Tuan, I969, 27). Chang has reconstructed a 'more moist environment with a thicker vegetation ... with rising temperature and increased water distribution' (1970, 176) for the area during the time of the development of the Neolithic. Most writers agree that the earliest form of cultivation in this area was a form of slash-and-burn. This is favourably adapted to open forest-not to steppe grassland. The reconstruction of the environment is of utmost significance in the understanding of specific neolithic development in the Chung Yuan, and also for the comprehension of a worldwide model of food production development.

Acknowledgement is made to the Canada Council for support of research on prehistoric man-land relationships in East Asia, and to R. G. Matson and R. Mathews, who have offered criticisms and comments.

BUTZER, K. 1971. Environment and archaeology. and edition (Chicago).

Chang, K. C. 1968. Archaeology of Ancient China (Yale).

1970. The beginnings of agriculture in the Far East, ANTIQUITY, XLIX, $175-85$.

Hо, P. T. 1969. Loess and the origins of Chinese agriculture, American Historical Review, Lxxv, I, $1-36$.

KIM, C. M. 1968. The nutrient-holding capacity of soils of different forest types in Korea, Ecolological Review, XVII, 2, 67-74.

LIU, T. S. and T. Y. CHANG. I962. The Loess of China, Acta Geologica Sinica, XLII (in Chinese).

OH, C. Y. I97I. A pollen analysis of peat sediments of Pyung-Taek County, Korea, Korean Yournal of Botany, xv, 3, 126-33 (in Korean).

sHIH, H. P. et al. 1963. Hsi-an pan p'o (Peking), (in Chinese).

TUAN, Y. F. 1969. China (Chicago).

UEYAMA, SHINPEI. 1969. The culture of the broadleaf evergreen forest zone (in Japanese).

WaNG, c. W. 1961. The forests of China, with a survey of grassland and desert vegetation. Maria Moors Cabot Foundation Publication No. 5 (Harvard).

\section{Drought and the decline of Mycenae: some comments}

Dr Oliver Dickinson, of the Department of Ancient History and Archaeology in the University of Birmingham, sends these comments on the article, 'Drought and the decline of Mycenae' by R. A. Bryson, H. H. Lamb and David L. Donley (I974, 46-5O). Professor Bryson replies on behalf of himself and his colleagues.

Archaeologists are often urged nowadays to show caution in their handling of scientific evidence; it is surely not too much to expect scientists to show equal care with archaeological evidence. In this respect, 'Drought and the decline of Mycenae' (Antiquity, 1974, 46-50) sets a bad example. The authors appear to have relied for an account of the archaeological evidence on a secondary work published several years ago by a scholar who is not a specialist in the field; they give no indication of expecting that any new evidence might have appeared since then, and their bibliography includes none of the absolutely basic work of $\mathrm{V}$. R. Desborough and A. M. Snodgrass. As a result, 


\section{NOTES AND NEWS}

their claim that Rhys Carpenter's drought hypothesis is 'the only one presently available that is consistent with extant evidence (my italics)' is open to severe criticism.

One of the two fundamental assumptions of the article is that Greece can be divided into a disaster area, where agriculture was completely disrupted, and a survival area, where it continued to flourish and to which there was substantial migration. The best evidence for any sort of disaster around the end of the thirteenth century $\mathrm{BC}$ is the destruction or abandonment of excavated sites; one might well expect wholesale abandonment in the disaster area. This is not the case; to name only the best-known sites, Mycenae, Tiryns, Argos and Asine in the Argolid, Thebes in Boeotia, Lefkandi in Euboea, Medeon (Ay. Theodoros) and Delphi in Phocis, Knossos, Phaistos, Palaikastro, and Khania in Crete, have all produced evidence of survival from the thirteenth century into the twelfth, often substantial and in some cases possibly representing an increase of population (e.g. Lefkandi). Even in the south Peloponnese, where there is plausible evidence for a considerable drop of population, there was often some survival at or near the old centres. It may be noted that the Linear B records of the palace at Pylos contain no indication that the state's agricultural basis was not functioning normally. There is no evidence that Attica received an influx of refugees; twelfth-century material is as scanty there as in many other provinces, best represented by the large cemetery at Perati on the east coast and comparatively rare at Athens until late in the century. It is possible to deduce that the population declined considerably, partly as a result of migration overseas, but that survivors tended to concentrate at the ancient local capitals and large towns of Mycenaean Greece, in all provinces.

The other assumption is that Mycenaean civilization was destroyed in a sudden cataclysm. On the contrary, the evidence suggests that the whole period I250-1 I $50 \mathrm{BC}$ was one of trouble in the Aegean, punctuated by 'disaster horizons', in which important sites were destroyed by fire and others were abandoned. The growing preoccupation with defence in the thirteenth century, to be seen in the construction or extension of fortifications at important sites and the securing of a water-supply within the walls at Mycenae, Tiryns, and Athens, suggests that warfare of some sort was involved. The evidence from destructions can be tabulated.

Mid-thirteenth century: Mycenae (houses outside walls), Tiryns (some evidence from citadel), Zygouries (large house), all in Argolid.

Last half of thirteenth century, quite possibly before end: Menelaion (large house, Laconia), Pylos (palace and town), with general disaster in Messenia, Thebes (palace).

End of thirteenth century: thorough burning of Mycenae and Tiryns citadels, also Dendra (Argolid), Ay. Kosmas (Attica), Gla (Boeotia), Krisa (Phocis), Teikhos Dymaion (Achaia), all fortified sites. Virtual end of palace-civilization. Early twelfth century: Lefkandi (whole town), Iolkos ('palace', Thessaly). Hints of trouble at Athens (abandonment of houses on North Slope of Acropolis)?

Mid-twelfth century: Mycenae, Tiryns, Teikhos Dymaion (? or later), Lefkandi (? partial).

(Sites overseas have been ignored; the dates are not all agreed, and are those that seem most plausible to me.)

The 'extant evidence' is thus extremely complex, and allows no easy solution; objections can be raised to any theory, even that of wholesale raiding, which could have caused all the destructions, but hardly depopulation on the scale often envisaged. Thorough acquaintance with the complexities is needed before further theories are produced.

\section{Professor R. A. Bryson writes:}

Dr Dickinson's point is well-taken, that the extant evidence on the decline of Mycenae is greater than that known to the authors of the article. However, if he were to carefully re-read the article and consider its purpose he would find that the authors were not trying to explain the decline but rather to test whether Carpenter's hypothesis on the decline could be backed by climatic evidence and thus not be ruled out on other than archaeological evidence.

At no point in the article did the authors assume, as alleged, that Greece could be 


\section{ANTIQUITY}

divided into two areas-'a disaster area, where agriculture was completely disrupted' and 'a survival area'. Only in reference to Carpenter's hypothesis was this mentioned. Nor was it stated, or assumed, as alleged, that 'Mycenaean civilization was destroyed in a sudden cataclysm'. In fact, no statement of any kind was made about the rapidity with which either climatic change or cultural response occurred or might have occurred.

Only two issues were central to the paper. The first was whether Carpenter's proposed drought pattern was possible, and the second was whether such a drought actually occurred

\section{A pottery drawing aid}

This addition to our occasional contributions on technical aids for archaeologists comes from Mr. B. F. N. Edwards, FSA, Archaeology Officer for Lancashire (Lancashire Record Office, Preston).

The device to be described is an aid to the drawing of pottery for archaeological purposes which is simple both to make and to use. It consists of a square of clear 'Perspex' ( 12 in. square is a useful size) on one side of which are incised a number of concentric circles. The diameters of these are indicated on the surface and a calibrated scale runs up the left side. Precise details, such as the interval between successive circles and the manner of indicating their diameters (or radii, if preferred) can be left to individual choice, as can the decision to employ metric units or otherwise.* My own, having been made some years ago, is non-metric and the interval between diameters of successive circles is $\frac{1}{4}$ in. The diameters are marked outside the circle to which they refer and a note incised on the device 'DIAM. INS. LINE INSIDE' reminds the user of the facts that diameters, not radii, are indicated; that they are in inches; and that the line lies inside the figure which refers to it. All incisions are easily done with a pair of dividers and lettering in reverse is easier to do than it looks, if one

- Not any more, please! The Production Editor is anxious to discard her conversion tables and be relieved of that tiresome chore, still imposed on her by some of our authors (Ed.). at the proposed time. Climatic, rather than archaeological, data was the basis of the analysis. The archaeological evidence cited by Dickinson does not seem inconsistent with a time of troubles induced, at least in part, by a prolonged drought. Certainly it does not disprove the climatic analysis. Perhaps people with Dr Dickinson's grasp of the archaeological data may someday determine the role that such a drought might have played in the history of Mycenae. We hope they will consider our analysis of the climate, not as a theory of cultural decline, but as an environmental factor pertinent to the archaeological analysis.

prefers all the scribing to be on the underside.

The method of use, seen in FIG. I $a$, where only a few circles are shown for the sake of clarity, is simply a refinement of the 'concentriccircles-on-paper' method of determining the size of rim from which a rim-sherd has been broken. Its use avoids the necessity of 'standing on one's head' and, more important, the relationship of the sherd to circles of smaller diameter than that with which it is being compared can be seen at the same time as the relationship to larger ones. It is suggested that the values of the circles should be placed in a line towards the top left corner, since this is the area least likely to be obscured by a righthanded user.

In FIG. I $b$ the device is seen used as a square, to help in the drawing of a profile of a complete vessel. This can be adapted to the drawing of a base-sherd plus some profile, or of a rim-sherd plus some wall. Having determined the diameter of the base (by measurement, if it is complete, or by the use of the device in the manner described above, if not) a circle of that diameter is drawn on a sheet of paper. One radius is drawn (XY) and produced beyond the circumference. The pot is centred on the circle and the device placed on the produced radius in such a manner that its vertical side touches the pot at its maximum (or maximum surviving) diameter. Point $A$ is marked on the produced radius and $\mathrm{XA}$, corresponding to the diameter 